\title{
PERFORMANCE-BASED DESIGN OF ENERGY PILE FOUNDATIONS
}

Alessandro F. Rotta Loria, Ph.D., P.E., Post-doctoral Researcher, Swiss Federal Institute of Technology in Lausanne, EPFL, Switzerland; Appointed Tenure Track Assistant Professor, Northwestern University, USA, alessandro.rottaloria@epfl.ch

\begin{abstract}
Over the past twenty years, an increasing amount of research has been performed to understand the multiphysical behavior and to address the geotechnical and structural design of so-called energy piles, i.e., deep foundations that can serve any superstructure as both structural supports and geothermal heat exchangers. The coupled application of thermal and mechanical loads to energy piles, due to their multifunctional operation, represents a challenge. Currently, knowledge about the response of energy piles subjected to thermal and mechanical loads is accessible, along with some design guidance. However, this knowledge is fragmented and no recognized performance-based design framework is available. Looking at such challenge, this paper presents a theoretical and experimental analysis of the multiphysical behavior of energy piles, as well as a performance-based design framework for such foundations. The work highlights that thermal loads involve effects that can be neglected in the design of energy piles at ultimate limit states and can be considered relevant only at serviceability limit states. Based on this result, the performance-based design of energy piles at ultimate limit states reduces to a conventional pile design process while the design at serviceability limit states must account for a number of proposed verifications.
\end{abstract}

Keywords: energy piles; thermo-mechanical behavior; analysis; performance-based design; framework;

\section{INTRODUCTION}

Over the past twenty years, much theoretical and empirical knowledge and many analysis tools have been made available to characterize the response of energy piles subjected to mechanical and thermal loads as well as to address the geotechnical and structural performance of such geostructures. In relatively recent years, design recommendations have been proposed (SIA-D0190, 2005; Ground Source Heat Pump Association, 2012; CFMS-SYNTEC-SOFFONS-FNTP, 2017) and studies addressing performance-based design approaches have been carried out (Xiao et al., 2016; Jelušič and Žlender, 2018). Despite the previous developments, a unified framework about the influence of mechanical and thermal loads on the behavior and performance of energy pile foundations and a recognized performance-based design methodology for the considered geostructures are currently unavailable.

To address the previous challenge, this paper provides a framework about the multiphysical behavior of energy piles and a performance-based design methodology that can be employed in many practical situations to address the response of such foundations to mechanical (e.g., axial) and thermal loads. In this context, an idealization of the thermo-mechanical behavior of energy piles is presented first. Next, an analysis of the response of energy piles, soils and soil-pile interfaces to mechanical and thermal loads is proposed. Then a performance-based design framework for energy piles is discussed. Finally, concluding remarks are summarized.

In this paper, specific reference is made to cylindrical energy piles made of reinforced that are subjected to axial and compressive mechanical loads as well as to thermal loads. The adopted sign convention considers compressive stresses, contractive strains and settlements to be positive.

\section{IDEALIZED THERMO-MECHANICAL BEHAVIOR OF ENERGY PILES Geotechnical features of energy piles}

The general equation that governs the vertical equilibrium of energy piles is 
$P+\frac{\pi D^{2}}{4} K_{h} w(z=0)+W+Q_{s, m o b}+Q_{b, m o b}=0$

where $P$ is the applied mechanical load, $D$ is the pile diameter, $K_{h}$ is the head stiffness of the structural element connected to the pile, $w(z=0)$ is the pile vertical head displacement (with $z$ being the vertical coordinate), $W$ is the pile weight, and $Q_{s, m o b}$ and $Q_{b, m o b}$ are the mobilized shaft and base capacities, respectively.

To distinguish the different mechanical response of energy piles subjected to mechanical and thermal loads, it is often useful to write both $Q_{s, m o b}$ and $Q_{b, m o b}$ in terms of a mechanical and a thermal contribution as

$Q_{s, m o b}=Q_{s, m o b}^{m}+Q_{s, m o b}^{t h}$

and

$Q_{b, m o b}=Q_{b, m o b}^{m}+Q_{b, m o b}^{t h}$

The reason for this is that in contrast to the influence of conventionally applied mechanical loads that cause a pile displacement in a unique direction (e.g., downward), thermal loads applied to energy piles generally involve two pile portions that displace in opposite directions from the so-called null point of the vertical displacement (located at a depth, $z_{N P, w}$ ) (Laloui et al., 2003). Accordingly, shear stress is mobilized in opposite directions at the pile shaft to ensure equilibrium with the surrounding soil from the so-called null point of the shear stress (generally located at a different depth, $z_{N P, \tau}$, than that of the null point of the vertical displacement) (Rotta Loria et al., 2018b). Based on the above, $Q_{s, m o b}^{t h}$ can be written as (Mimouni and Laloui, 2014)

$Q_{s, m o b}^{t h}=Q_{s, m o b, u p}+Q_{s, m o b, \text { down }}$

where $Q_{s, m o b, u p}$ and $Q_{s, m o b, d o w n}$ are the portions of shaft capacity mobilized above and below the null point of the shear stress, respectively. For cylindrical energy piles of diameter, $D$, and length, $L$ (Mimouni and Laloui, 2014)

$Q_{s, m o b, u p}=\pi D \int_{0}^{z_{N P, \tau}} \tau d z$

and

$Q_{s, \text { mob,down }}=\pi D \int_{Z_{N P, \tau}}^{L} \tau d z$

where $\tau$ is the shear stress.

In many situations, a reversible behavior of the ground surrounding energy piles is associated with thermal loads, applied alone or in conjunction with mechanical loads (see, e.g., Laloui et al. (2003) and Wang et al. (2014)). Therefore, thermo-elasticity theory can effectively describe the geotechnical response of such foundations (Rotta Loria and Laloui, 2017c). However, significant magnitudes of thermal loads, applied alone or in conjunction with mechanical loads, can cause irreversible, i.e., plastic, phenomena in the ground adjacent to energy piles (see, e.g., Sutman et al. (2015)). When plastic phenomena develop in the ground, stress redistribution around a pile, together with associated 
redistributions of the vertical stress and displacement along the pile, occurs for further loading. For an energy pile subjected to a given temperature variation in a soil characterized by a linear elasto-plastic behavior, this redistribution involves, with respect to a linear elastic behavior, (i) a lower development of shear stress at the pile-soil interface, (ii) a movement of the null points, (iii) a greater vertical displacement at the pile head and (iv) a lower development of vertical stress in the pile as a consequence of the lower restraint characterizing the system (Rotta Loria et al., 2015). The history, magnitude and sequence of the applied loads become crucial aspects of the problem for further loading (or unloading).

\section{Structural features of energy piles}

Because in most situations the imposed deformation caused on energy piles by thermal loads does not occur under free expansion conditions due to the presence of the ground and the superstructure, a thermally induced stress arises along such foundations. This stress influences energy piles in conjunction with that caused by the potentially applied mechanical loads. The higher the restraint provided by the ground and the superstructure, the higher the blocked thermally induced strain, $\varepsilon_{b}^{t h}$, the lower the observed thermally induced strain, $\varepsilon_{o}^{t h}$, and the greater the observed thermally induced stress, $\sigma_{o}^{\text {th }}$, along energy piles (cf., Fig. 1).
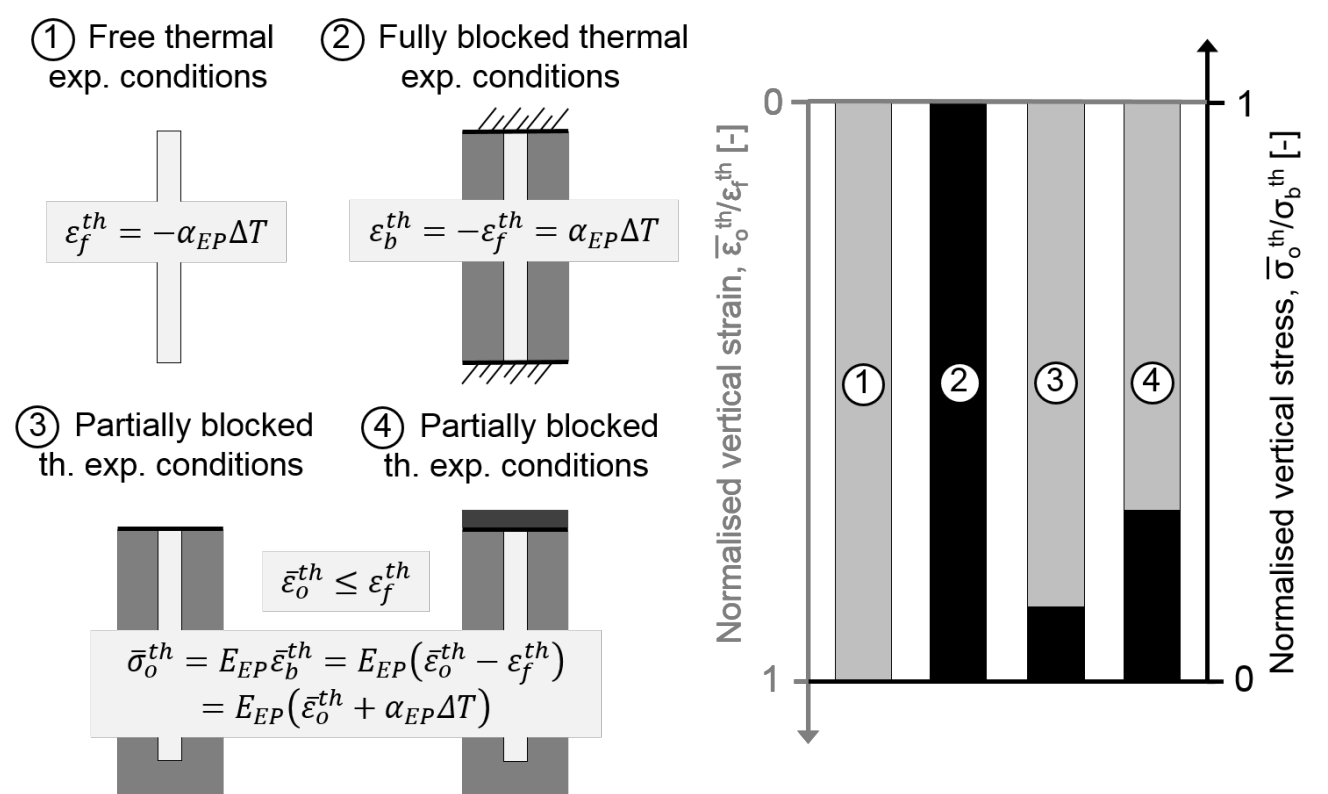

Fig. 1: Impact of system restraint on the thermally induced vertical strain and stress in energy piles.

Currently, a reversible behavior of reinforced concrete that constitutes in most cases energy piles should be incorporated into the design, based on the assumptions of (i) uncracked cross-sections, (ii) linear stress-strain relationships and (iii) mean values of the modulus of elasticity (see, e.g., EN 1992, 2004). In this context, thermo-elasticity theory can effectively describe the thermo-mechanical behavior of energy piles in addition to the behavior of the surrounding ground. In a one-dimensional framework, this involves (Laloui et al., 2003)

$$
\sigma_{o}^{t h}=E_{E P} \varepsilon_{b}^{t h}=E_{E P}\left(\varepsilon_{o}^{t h}-\varepsilon_{f}^{t h}\right)=E_{E P}\left(\varepsilon_{o}^{t h}+\alpha_{E P} \Delta T\right)=E_{E P} \alpha_{E P} \Delta T(1-D O F)
$$


where $E_{E P}$ is the Young's modulus of the pile, $\varepsilon_{f}^{t h}=-\alpha_{E P} \Delta T$ is the strain under free thermal expansion conditions, $\alpha_{E P}$ is the linear thermal expansion coefficient of the pile, $\Delta T$ is the applied temperature change, and $D O F=\varepsilon_{o}^{t h} / \varepsilon_{f}^{t h}$ is the pile degree of freedom.

However, although no experimental evidence that corroborates the following is available for energy piles, significant magnitudes of thermal loads, applied alone or in conjunction with mechanical loads, may cause irreversible phenomena in reinforced concrete. The phenomena that may characterize the irreversible behavior of reinforced concrete sections subjected to loads of significant magnitudes are the development of cracks and the rupture of the reinforcement steel.

Before reaching the maximum tensile strength of concrete, reinforced concrete cross-sections behave following a linear elastic behavior. When concrete cracks, a sudden decrease in the stiffness of the sections occurs, and stress redistribution occurs from concrete to steel. In this case, the axial strain is

$\varepsilon_{z}=\frac{f_{c t}}{E_{c}}$

where $f_{c t}$ and $E_{c}$ are the tensile strength and the Young's modulus of concrete, respectively. The axial force needed to crack reinforced concrete cross-sections is

$N_{c r}=E_{E P} A_{E P} \varepsilon_{z}=E_{c} A_{E P}\left[1+\rho_{r}\left(n_{r c}-1\right)\right] \frac{f_{c t}}{E_{c}}=f_{c t} A_{E P}\left[1+\rho_{r}\left(n_{r c}-1\right)\right] \approx f_{c t} A_{E P}$

where $A_{E P}$ is the cross-section of the energy pile, $\rho_{r}=A_{r} / A_{E P}$ is the reinforcement ratio of the crosssection (with $A_{r}$ the cross-sectional area of the longitudinal reinforcement), and $n_{r c}=E_{r} / E_{c}$ is the steel-to-concrete stiffness ratio (with $E_{r}$ the Young's modulus of the reinforcement steel).

The axial force mobilized by concrete and steel upon cracking can be determined, respectively, as

$N_{c r, c}=A_{c} f_{c t}=f_{c t} A_{E P}\left(1-\rho_{r}\right) \approx f_{c t} A_{E P}$

$N_{c r, r}=N_{c r} \frac{n_{r c} \rho_{r}}{1+\rho_{r}\left(n_{r c}-1\right)}=f_{c t} A_{E P} n_{r c} \rho_{r}$

where $A_{c}=A_{E P}-A_{r}$ is the concrete area. After concrete cracks in reinforced concrete cross-sections, only the steel contributes to the resistance against the action effects. In this case,

$E_{E P} A_{E P}=E_{r} A_{r}$

$N=N_{r}$

$N_{R}=f_{y} A_{r}=f_{y} \rho_{r} A_{E P}$

where $N_{r}$ is the proportion of axial force $N$ received by the reinforcement, $N_{R}$ is the resisting axial force, and $f_{y}$ is the steel yield strength.

The actual response of whole reinforced concrete members differs from that of single mean crosssections described above unless a simultaneous occurrence of cracks is assumed, because cracking occurs progressively. Furthermore, the response of any reinforced concrete members differs from that of 
the only reinforcement steel because the concrete cannot crack everywhere and the concrete between two cracks contributes to their stiffness (so-called tension-stiffening phenomenon).

\section{Thermo-mechanical schemes for energy piles}

To further characterize the response of single energy piles to mechanical and thermal loads, thermomechanical schemes can be employed. While original schemes were proposed by Bourne-Webb et al. (2009) and Bourne-Webb et al. (2011) with reference to experimental data, revised and novel schemes based on linear thermo-elasticity theory are proposed hereafter (Rotta Loria and Laloui, 2019), with the advantage that they (i) show simple yet realistic evolutions of the influence of mechanical and thermal loads that can be superimposed via the elastic superposition principle in all situations in which reversible conditions occur and (ii) serve as a reference for developing considerations related to more involved situations in which irreversible conditions occur. Within this context, the energy piles are characterized by a thermo-elastic behavior, whereas the deep surrounding soil mass exhibits an elastic behavior.

The mechanical response of an energy pile with no base and head restraints to an axial mechanical load, a heating or cooling thermal load, and a mechanical and thermal load is depicted in Fig. 2. For the case of vertical mechanical loading only (cf., Fig. 2(a)), equation (1) can be rewritten as

$P+Q_{s, m o b}^{m}=0$

The application of an axial mechanical load to the pile head causes an approximately linearly decreasing distribution of compressive vertical stress $\sigma_{z}$ along the pile and uniform and approximately constant distributions of positive shear stress $\tau$ at the pile-soil interface and downward pile displacement $w$ with depth $z$. The higher the pile stiffness, the more uniform and linear the distribution of $\sigma_{z}$ with $z$, and the more uniform and constant the distributions of $\tau$ and $w$ with $z$. Soil layering causes a less uniform distribution of all the considered variables. Stronger mechanical loads cause linearly greater stress and displacement variations.

For the case of thermal loading only (cf., Fig. 2(b-c)), equation (1) can be rewritten as

$Q_{s, m o b}^{t h}=Q_{s, m o b, u p}+Q_{s, m o b, \text { down }}=0$

The application of a heating or cooling thermal load to the pile causes a non-linear distribution of $\sigma_{z}$ with $z$ (symmetrical for heating and cooling), which is characterized by a maximum that coincides with the mid-length of the energy pile, where the null points of the vertical displacement and shear stress are also located. The application of a heating thermal load mobilizes negative shear stress and causes heave for the energy pile portion above the null points, while it mobilizes positive shear stress and causes settlement for the pile portion below the null points. The shear stress and vertical displacement caused by a heating thermal load develop in the opposite direction compared to those caused by a mechanical load above the null points, whereas these develop in the same direction below the null points. The opposite is true for a cooling thermal load. Shear stress and vertical displacement evolve approximately linearly with depth. The higher the pile stiffness, the more uniform the evolution of $\sigma_{z}$ with $z$, and the lower the variation of $\sigma_{z}$ for the same applied thermal load. Similarly, the higher the pile stiffness, the more uniform the evolutions of $\tau$ and $w$ but the higher their variation. Stronger thermal loads cause linearly greater stress and displacement variations.

For the case of mechanical and thermal loading (cf., Fig. 2(d-e)), equation (1) can be rewritten as 


$$
P+Q_{s, m o b}=P+Q_{s, m o b}^{m}+Q_{s, m o b}^{t h}=0
$$

The distributions of vertical stress and shear stress with depth as well as of vertical displacement can be obtained via superposition of the previous ones. Tensile stress along the energy piles can arise for low magnitudes of applied mechanical loads and significant cooling.
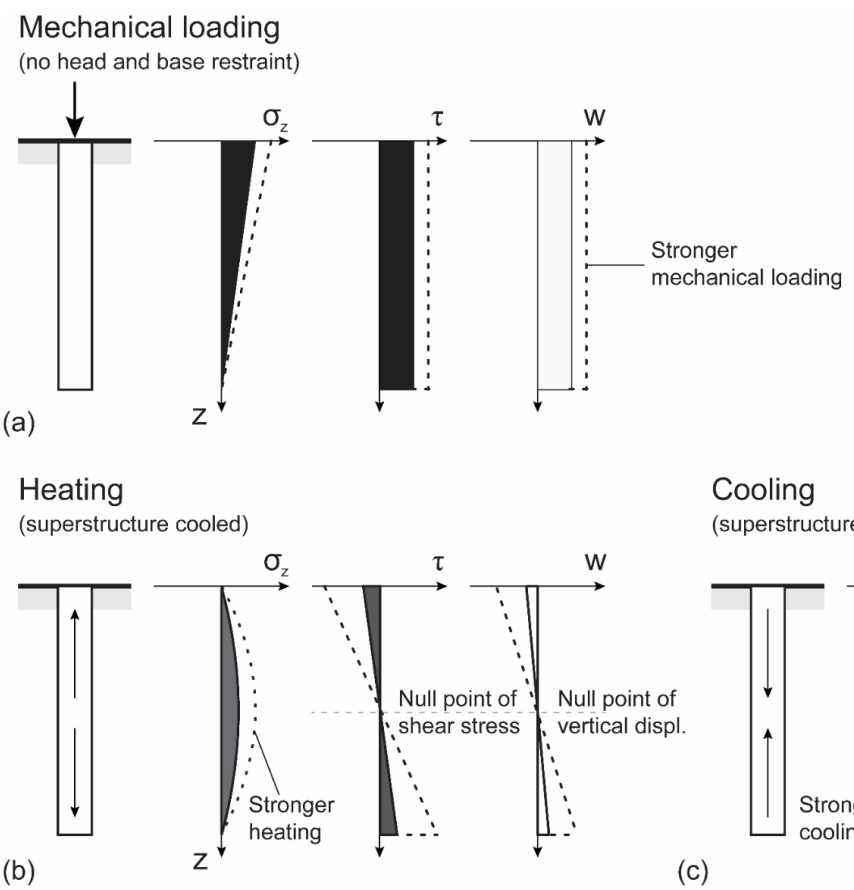

\section{Cooling}

(superstructure heated)

(c)

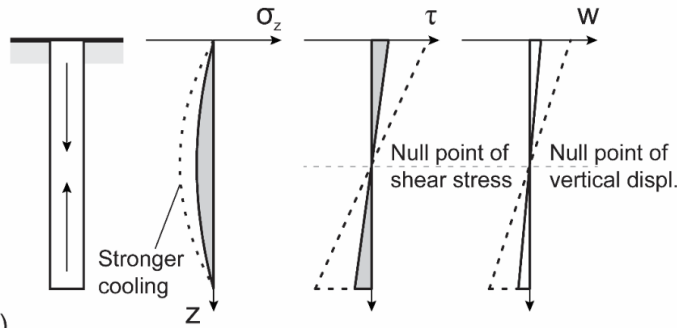

Mechanical loading and heating

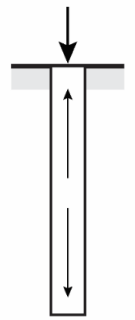

(d)

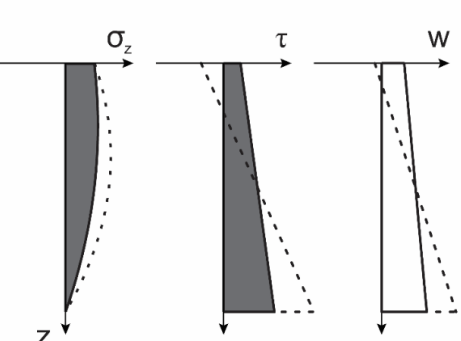

(e)

Mechanical loading and cooling
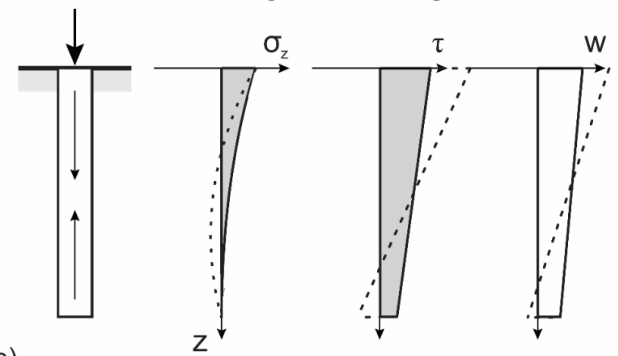

Fig. 2: Thermo-mechanical schemes for energy piles characterized by no base and head restraints.

The mechanical response of an energy pile with base or head restraints to an axial mechanical load, a heating thermal load, and a mechanical and heating thermal load is depicted in Fig. 3. For the case of vertical mechanical loading only (cf., Fig. 3(a-b)), equation (1) can be rewritten as

$P+Q_{s, m o b}^{m}+Q_{b, m o b}^{m}=0$

where only the base restraint is present, whereas

$P+\pi \frac{D^{2}}{4} K_{h} w^{m}(z=0)+Q_{s, m o b}^{m}=0$ 
where only the head restraint is present (with $w^{m}(z=0)$ being the pile vertical head displacement caused by the mechanical load).

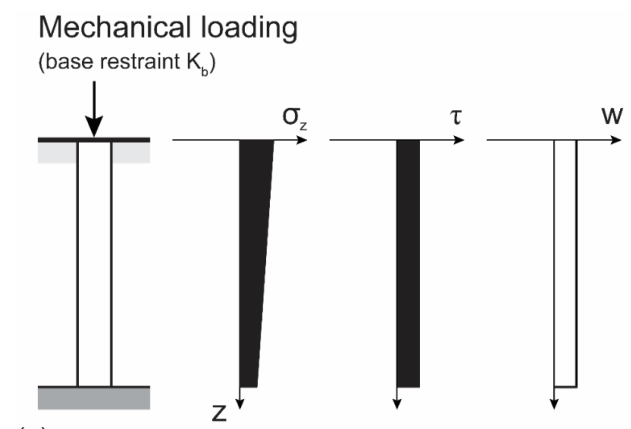

(a)

Heating

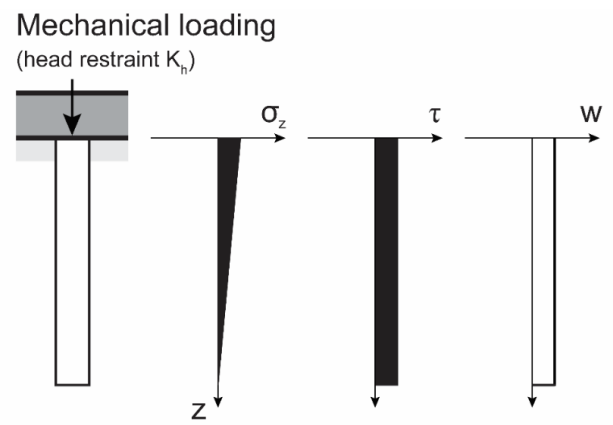

(b)

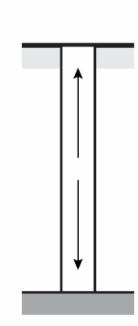

(c)

Mechanical loading and heating

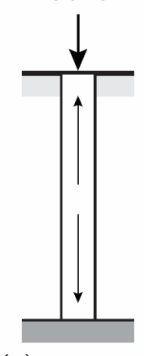

(e)

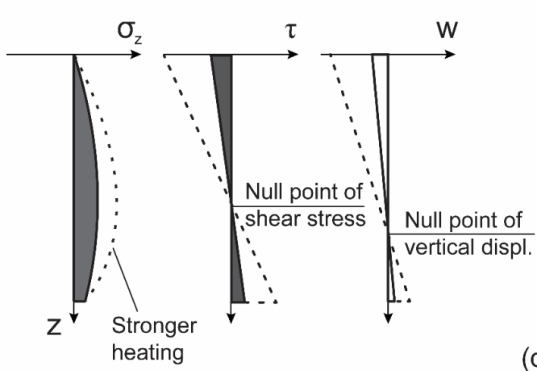

Heating

(d)

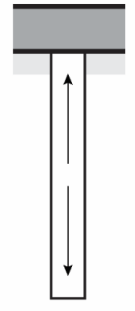

d)

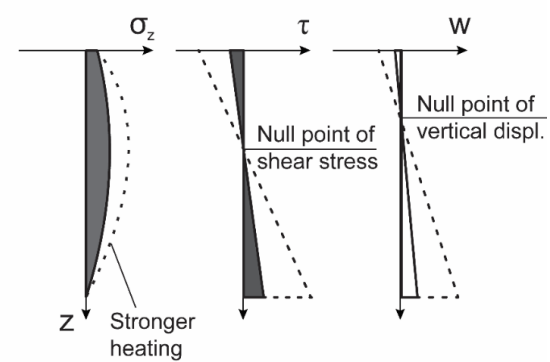

Mechanical loading and heating
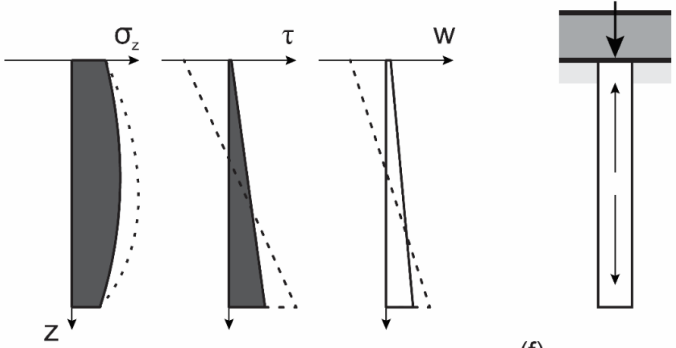

(f)

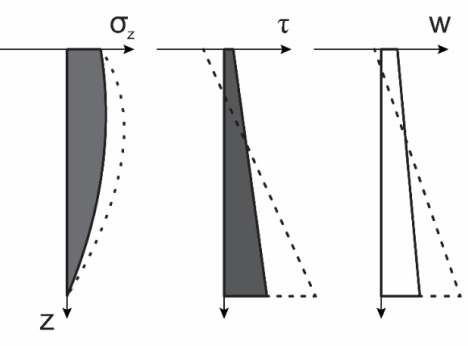

Fig. 3: Thermo-mechanical schemes for energy piles characterized by base or head restraints.

When a base restraint is present, a greater average vertical stress $\sigma_{z}$ (with a value corresponding to $P$ at the pile head) and lower shear stress $\tau$ and vertical displacement $w$ develop along the pile compared to the case of no base and head restraints. This phenomenon arises because of the contribution provided by the base capacity to the vertical pile equilibrium. In these schemes, the base capacity mobilizes at the same time as the shaft capacity for any magnitude of applied load, even though this is not necessarily the case in reality.

When a head restraint is present, a smaller average vertical stress $\sigma_{z}$ (with a corresponding value lower than that of $P$ at the pile head) and lower shear stress and vertical displacement variations develop along the pile compared to the case of no base and head restraints. This phenomenon arises because the head restraint reduces the effect of the downward mechanical load. This effect vanishes when the interplay between the mechanical load and the head restraint is not considered because the latter term is neglected. The consequence of such an approach is a pile response to mechanical loading equal to that of the case of no base and head restraints (i.e., equations (15) and (19) coincide).

For the case of heating thermal loading only (cf., Fig. 3(c-d)), equation (1) can be rewritten as 
$Q_{s, m o b}^{t h}+Q_{b, m o b}^{t h}=0$

where only the base restraint is present, whereas

$\pi \frac{D^{2}}{4} K_{h} w^{t h}(z=0)+Q_{s, m o b}^{t h}=0$

where only the head restraint is present (with $w^{\text {th }}(z=0)$ being the pile vertical head displacement caused by the thermal load).

Different from the situation where no base or head restraints are present, when either a base or head restraint is present, vertical stress $\sigma_{z}$ is generated at the restrained pile end by the applied thermal load. The vertical stress distribution is greater than that in the case with no base and head restraints, in accordance with the discussed effect of the higher restraint of the system. The null points of the vertical displacement and shear stress do not coincide but are shifted towards the region of the system characterized by the higher restraint. Lower vertical displacement develops towards the region of the system characterized by higher restraint, while higher displacement develops towards the region characterized by lower restraint compared to the case where the null points are located at the mid-length of the pile. A cooling thermal load yields a symmetrical response of the energy pile. In reality, the reduction of the compressive stress experienced at the pile toe for the case where a base restraint is present can attain at most the sum of any vertical mechanical load applied to the pile and its weight. This phenomenon occurs when soils cannot withstand tensile stress.

For the case of mechanical and heating thermal loading (cf., Fig. 3(e-f)), equation (1) can be rewritten as

$P+Q_{s, m o b}+Q_{b, m o b}=0$

where the base restraint is present, whereas

$P+\pi \frac{D^{2}}{4} K_{h} w(z=0)+Q_{s, m o b}=0$

where the head restraint is present (with $w(z=0)=w^{m+t h}(z=0)$ ). The distributions of vertical stress and shear stress with depth as well as of vertical displacement can be obtained via superposition of the previous ones.

The mechanical response of an energy pile with base and head restraints to an axial mechanical load, a heating thermal load, and a mechanical and heating thermal load is depicted in Fig. 4. Two different cases involving a base restraint equal to the head restraint and a base restraint equal to one-half of the head restraint are considered. For the case of vertical mechanical loading only (cf., Fig. 4(a-b)), equation (1) can be rewritten as

$P+\pi \frac{D^{2}}{4} K_{h} w^{m}(z=0)+Q_{s, m o b}^{m}+Q_{b, m o b}^{m}=0$

In the proposed schemes, the effect of the presence of the slab on the influence of the mechanical load on the pile response is considered. Hence, lower developments of vertical stress and shear stress as well as of vertical displacement are observed for a higher head restraint, compared to the case of a base restraint only. This behavior may be expected in reality. However, many analyses and designs usually 
do not account for the interplay between the action of the mechanical load and the head restraint, neglecting the latter term.

For the case of heating thermal loading only (cf., Fig. 4(c-d)), equation (1) can be rewritten as

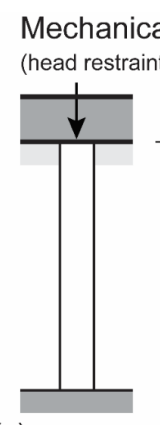

(a)

Heating

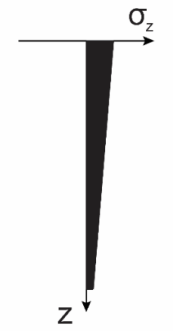

$z^{\prime}$

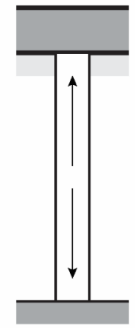

(c)

\begin{abstract}
Mechanical loading and heating
\end{abstract}

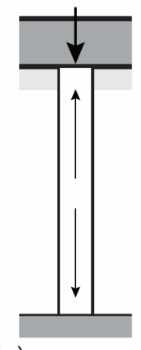

(e)

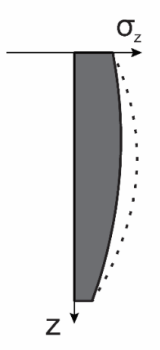

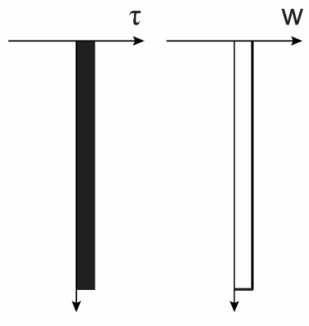

(b)

Heating
Mechanical loading

(head restraint equal to double the base restraint, i.e., $\mathrm{K}_{\mathrm{h}}=2 \mathrm{~K}_{\mathrm{b}}$ )

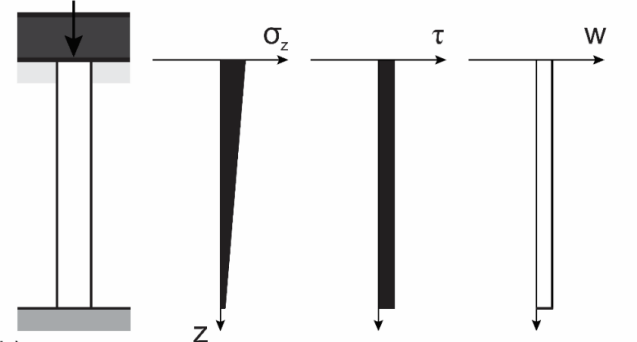

(1)

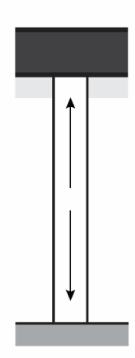

(d)

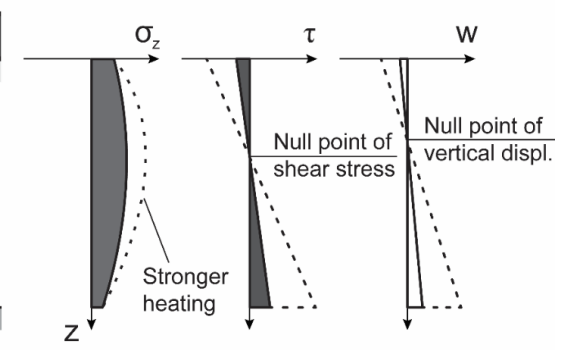

Mechanical loading and heating

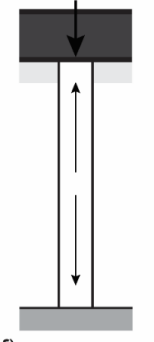

(f)

Fig. 4: Thermo-mechanical schemes for energy piles characterized by base and head restraints.

$\pi \frac{D^{2}}{4} K_{h} w^{t h}(z=0)+Q_{s, m o b}^{t h}+Q_{b, m o b}^{t h}=0$

The vertical stress $\sigma_{z}$ caused by the thermal load is characterized by a symmetrical distribution with depth $Z$ when the base and head restraints are of the same magnitude, whereas by an asymmetrical distribution when different magnitudes characterize the end restraints. Higher stress develops towards the region of the system characterized by higher restraint. The higher the restraint provided by the end conditions, the higher the vertical stress and the lower the mobilized shear stress and vertical displacement.

For the case of mechanical and heating thermal loading (cf., Fig. 4(e-f)), equation (1) governs the system, the response of which can be obtained via superposition of the analyzed situations. 


\section{OBSERVED THERMO-MECHANICAL BEHAVIOR OF ENERGY PILES Response of single and groups of energy piles subjected to thermo-mechanical loads}

In addition to the previous theoretical framework addressing the response of energy piles to mechanical and thermal loads, a substantial amount of experimental knowledge can be considered to comprehensively characterize such foundations as well as to develop analysis and design considerations. Knowledge from full-scale in situ tests (Laloui et al., 2003; Bourne-Webb et al., 2009; McCartney and Murphy, 2012; Murphy et al., 2015; Murphy and McCartney, 2015; Wang et al., 2014; Akrouch et al., 2014; Sutman et al., 2015; You et al., 2016; Sutman et al., 2017; Luo et al., 2017; Chen et al., 2017; Allani et al., 2017); McCartney and Murphy (2017), model-scale laboratory tests (Kalantidou et al., 2012; Yavari et al., 2014; Kramer and Basu, 2014; Marto et al., 2015; Yavari et al., 2016b; Nguyen et al., 2017; Liu et al., 2018) and centrifuge tests (Stewart and McCartney, 2014; Ng et al., 2014; Goode and McCartney, 2015; Ng et al., 2015; Ng et al., 2016a) of single energy piles is available. Along with the previous experimental knowledge, theoretical developments including numerical investigations (Laloui et al., 2006; Suryatriyastuti et al., 2012; Olgun et al., 2014; Mimouni and Laloui, 2014; Batini et al., 2015; Rotta Loria et al., 2015; Saggu and Chakraborty, 2015; Bourne-Webb et al., 2016; Gawecka et al., 2016; Ng et al., 2016b; Adinolfi et al., 2018; Rammal et al., 2018; Rui and Soga, 2018; Banerjee et al., 2018) and analysis tools (Knellwolf et al., 2011; Pasten and Santamarina, 2014; Suryatriyastuti et al., 2014) for single energy piles are also accessible.

Along with the previous contributions addressing single energy piles, increasing research is available to characterize the response of groups of energy piles subjected to mechanical and thermal loads. In this context, full-scale in situ tests (Mimouni and Laloui, 2015; Rotta Loria and Laloui, 2017c; Rotta Loria and Laloui, 2018c), numerical analyses (Salciarini et al., 2015; Jeong et al., 2014; Di Donna and Laloui, 2014; Suryatriyastuti et al., 2015; Di Donna et al., 2016; Salciarini et al., 2017; Saggu and Chakraborty, 2016) and analysis tools are available (Rotta Loria and Laloui, 2016; Rotta Loria and Laloui, 2017b; Rotta Loria and Laloui, 2017a; Rotta Loria et al., 2018b; Rotta Loria et al., 2017). Based on all of the aforementioned contributions, the following complementary features are worth noting to characterize the response of energy piles.

Group effects and interactions occur among energy piles located sufficiently close to each other because of the presence of and loadings (e.g., mechanical and thermal) on the neighboring piles. These phenomena involve a different response of the piles in the group than that of an isolated pile. Figure 5 provides an example of the influence of thermally induced group effects on the response of a full-scale energy pile group tested in situ out over practical time-scales of geothermal operations by Rotta Loria and Laloui (2017d) and Rotta Loria and Laloui (2017c). When energy piles are located sufficiently close to each other, greater average thermally induced vertical strains arise for the same average temperature change along the piles as the number of operating energy piles increases (cf., Fig. 5(a)). Therefore, analyses of the deformation of single energy piles are not exhaustive and cannot represent the actual behavior of energy piles operating in a group. At the same time, because of the previously commented interplay between observed thermally induced strain and stress, lower average thermally induced vertical stresses arise for the same average temperature change along the piles as the number of operating energy piles increases (cf., Fig. 5(b)). Therefore, analyses of single energy piles are considered useful, particularly in preliminary design stages. Provided that similar head restraint conditions are considered for a given energy pile in a soil deposit, these analyses will always provide a conservative estimate of the thermally induced vertical stress along operating energy piles in a group. The commented influence of thermal loads in the context of group effects and interactions on energy pile behavior is comparable to that of mechanical loads, which causes, for example, a greater pile group deformation under the same average load (Poulos and Davis, 1980; Fleming et al., 2008). 
At successive stages of the geothermal operation of energy piles, a noteworthy volume of soil can be subjected to a temperature change. This phenomenon involves an influence of the thermally induced soil deformation on the deformation of piles that depends on the value of soil-pile thermal expansion coefficient ratio, $X=\alpha_{\text {soil }} / \alpha_{E P}$ (where $\alpha_{\text {soil }}$ is the linear thermal expansion coefficient of the soil). For $X \leq 1$, the response of energy piles follows the previously discussed framework, with $0 \leq D O F \leq 1$. That is, compressive stress is caused by energy pile heating and tensile stress is caused by energy pile cooling (actually coinciding with a reduction of compressive stress). For $X>1$, a different response of the energy piles than that previously described can occur, with $D O F>1$. That is, tensile stress can be caused by energy pile heating and compressive stress can be caused by energy pile cooling. The reason for this is that, in such situations, the thermally induced soil deformation governs the overall deformation of energy pile foundations (Rotta Loria and Laloui, 2017c; Rotta Loria and Laloui, 2018c).
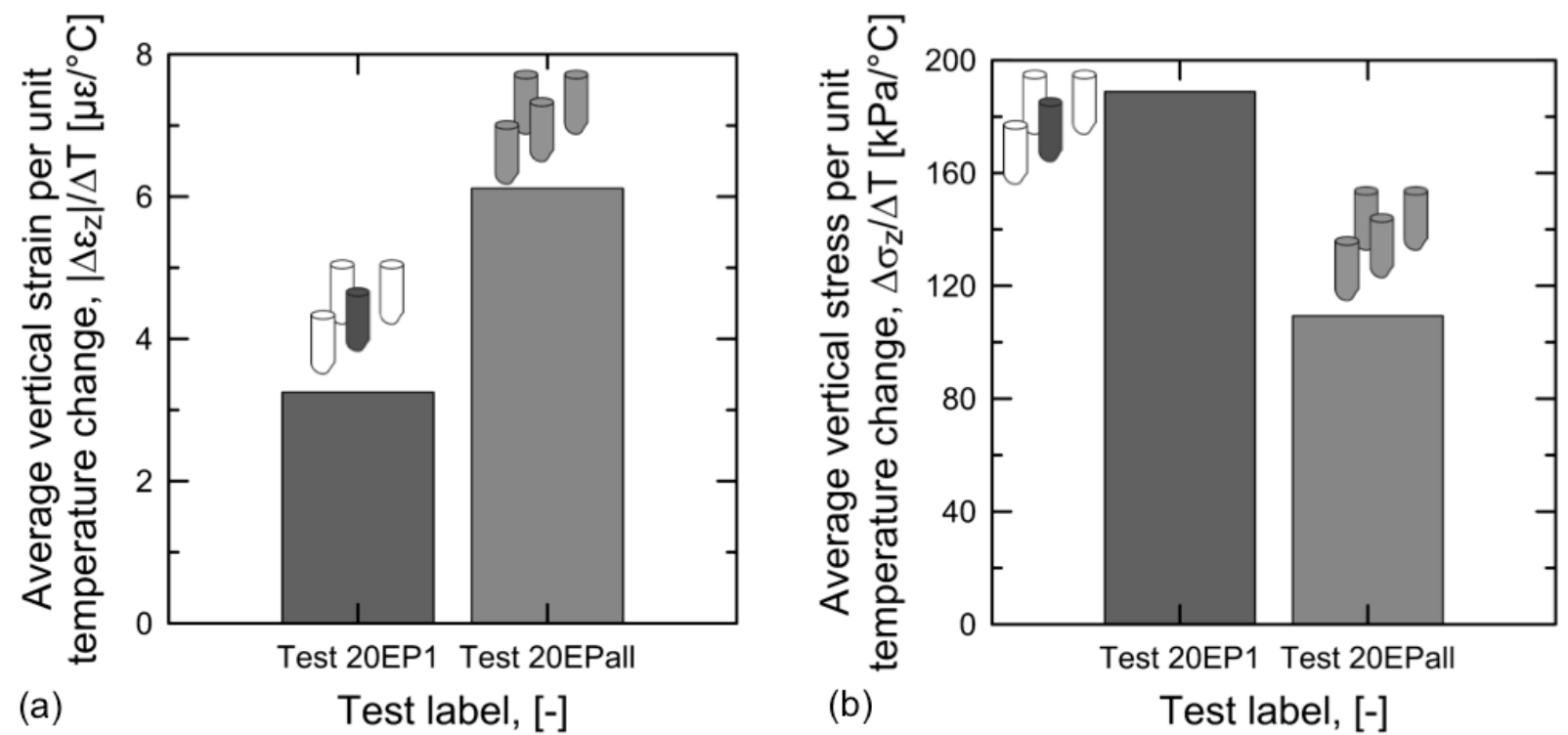

Fig. 5: Average thermally induced (a) strain and (b) stress developed along energy piles for an increasing number of piles operating as geothermal heat exchangers (data from Rotta Loria and Laloui (2017c) and Rotta Loria and Laloui (2018c).

\section{Response of soils subjected to thermo-mechanical loads}

Besides the aforementioned knowledge on the response of energy piles to mechanical and thermal loads, extensive experimental research on the behavior of both coarse- and fine-grained soils is accessible (see, e.g., Campanella and Mitchell, 1968; Plum and Esrig, 1969; Demars and Charles, 1981; Baldi et al., 1988; Hueckel and Baldi, 1990; Burghignoli et al., 2000; Cekerevac and Laloui, 2004; Vega and McCartney, 2014; Di Donna and Laloui, 2015; Agar et al., 1986; Agar et al., 1987; McCartney et al., 2018; Zhou et al., 2017; Ng and Zhou, 2017). Based on these developments, bearing in mind that in most practical situations drained conditions are ensured throughout the heating and cooling of energy piles, the following considerations can be made.

When temperature increases, all the constituents of a soil (i.e., the solid particles and the water constituting the soil matrix under the assumption of fully saturated conditions) expand. In drained conditions, thermal expansion and rearrangement of the solid particles occur while the pore water pressure caused by the expansion of this liquid dissipates. When temperature decreases down to $0{ }^{\circ} \mathrm{C}$, a contraction of the soil constituents is observed. 
Coarse-grained soils are weakly affected by temperature variations, considering both volumetric and deviatoric behaviors. The volumetric behavior of coarse-grained soils subjected to temperature changes is governed by the elastic thermal expansion of its constituents and is thus reversible upon heatingcooling cycles. Only at low relative densities an irreversible behavior upon heating may be observed.

Fine-grained soils are far more sensitive to temperature variations than coarse-grained soils because the thermal expansion of the grains is usually negligible with respect to the effects of temperature related to the modification of the internal forces equilibrium (Cekerevac and Laloui, 2004). In these situations, the thermal volume change of the adsorbed water and the solid particles modify the equilibrium of the internal attractive and repulsive forces. Figure 6 shows an example of the influence of thermal loads on the volumetric behavior of fine-grained soils based on the results of laboratory tests presented by Di Donna and Laloui (2015). Fine-grained soils subjected to temperature changes can produce either a contractive or a dilative volume variation, depending on their overconsolidation ratio, OCR. Under normally consolidated conditions (NC), fine-grained soils contract when heated and a significant part of this deformation is irreversible upon cooling (cf., Fig. 6(a)). This phenomenon is unusual for any material and can be interpreted as a densification phenomenon (i.e., thermal consolidation or thermal collapse) under no changes in effective stress. When thermal cycles are applied to fine-grained soils under normally consolidated conditions, most of the thermally induced plastic deformation is observed during the first heating-cooling cycle, followed by an accommodative behavior during the subsequent ones. The increments of irreversible deformation become smaller cycle after cycle until stabilization. In the end, the material stress state tends to remain inside the elastic domain showing a reversible expansion and contraction during heating and cooling, respectively. Under highly overconsolidated (OC) conditions, fine-grained soils expand upon heating while they contract reversibly upon cooling (cf., Fig. 6(a)). Between these two extreme cases there is an intermediate one represented by slightly over consolidated fine-grained soils. In this case, fine-grained soils show an initial expansion and a subsequent contraction during heating, followed by a tendency towards contraction during cooling. When subjected to increasing thermal loads, fine-grained soils are characterized by so-called thermal softening phenomenon, i.e., a decrease of the apparent preconsolidation pressure at constant void ratio for increasing temperature (cf., Fig. 6(b)). When subjected to significant magnitudes of thermal loads, fine-grained soils can show a temperature sensitivity of their elastic properties (Eslami et al., 2017). However, this sensitivity is limited in magnitude if not absent in many situations. Based on this fact, this thermally induced effect can be neglected in design unless particularly sensitive soils are encountered.

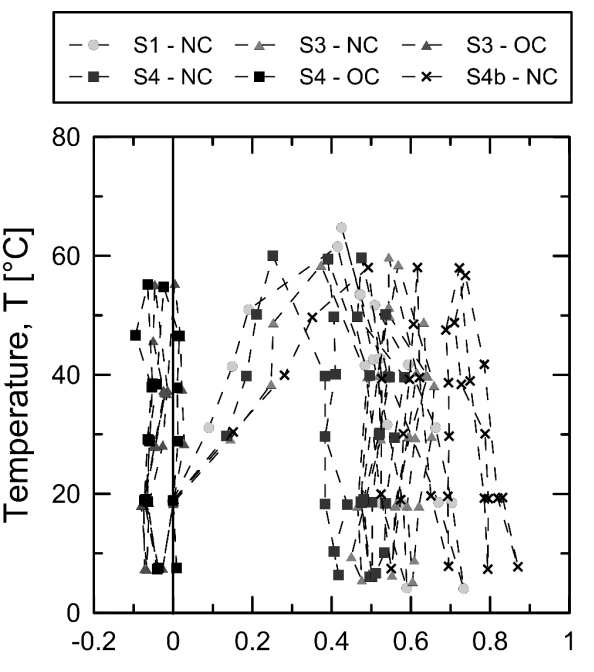

(a) Volumetric strain, $\varepsilon_{\mathrm{v}}$ [\%]

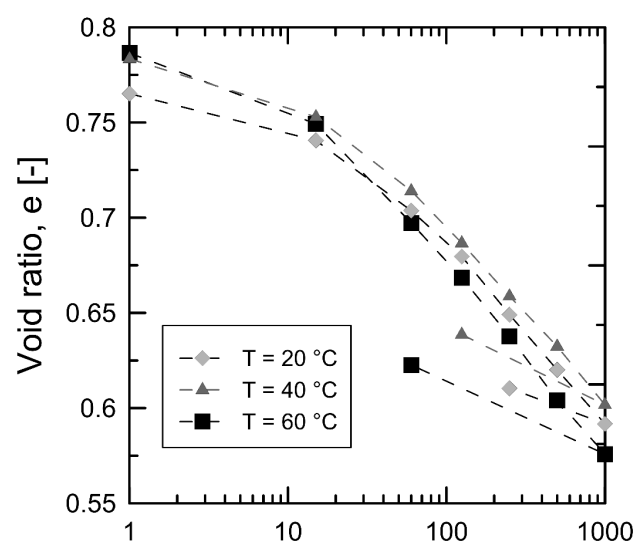

(b) Vertical effective stress, $\sigma_{v}^{\prime}[\mathrm{kPa}]$

Fig. 6: Volumetric response of fine-grained soils (a) at different temperatures and (b) under thermal cyclic loading (redrawn after Di Donna and Laloui (2015)). 


\section{Behavior of soil-concrete interfaces subjected to thermo-mechanical loads}

In addition to the previous knowledge, various experimental laboratory tests are also available to address the response of soil-concrete interfaces subjected to mechanical and thermal loads (see, e.g., Di Donna and Laloui (2015); Vega and McCartney (2014); Di Donna et al. (2015); and Yavari et al. (2016a)). Based on these developments, the following complementary considerations can be made.

Interfaces between concrete of varying roughness and both coarse- and fine-grained soils show a limited sensitivity to temperature changes. Figure 7 provides an example of this evidence for sand- and clayconcrete interfaces tested under various thermo-mechanical loading paths through experimental interface shear laboratory tests by Di Donna et al. (2015). Interfaces between concrete and coarsegrained soils do not appear to be affected by monotonic and cyclic temperature changes (cf., Fig. 7(a)). This result is corroborated by the limited sensitivity of coarse-grained soils to temperature. A more notable yet limited sensitivity to temperature can be observed for interfaces between concrete and finegrained soils, with a potential increase in the shear strength for increasing temperatures for normally consolidated fine-grained soils (cf., Fig. 7(b)). In this context, because of the thermally induced collapse of the soil, the interface angle of shear strength can slightly decrease while the adhesion between the soil and the concrete can increase with increasing temperatures. A mechanical degradation of the soilconcrete interface due to the repeated shearing (e.g., caused by a mechanically or thermally induced solicitation) can be observed. However, this phenomenon is considered independent of temperature. Based on this consideration, the effects of temperature on the shear strength parameters can be neglected in design unless particularly sensitive soils are encountered. This approach is in accordance with the French recommendations (CFMS-SYNTEC-SOFFONS-FNTP, 2017).
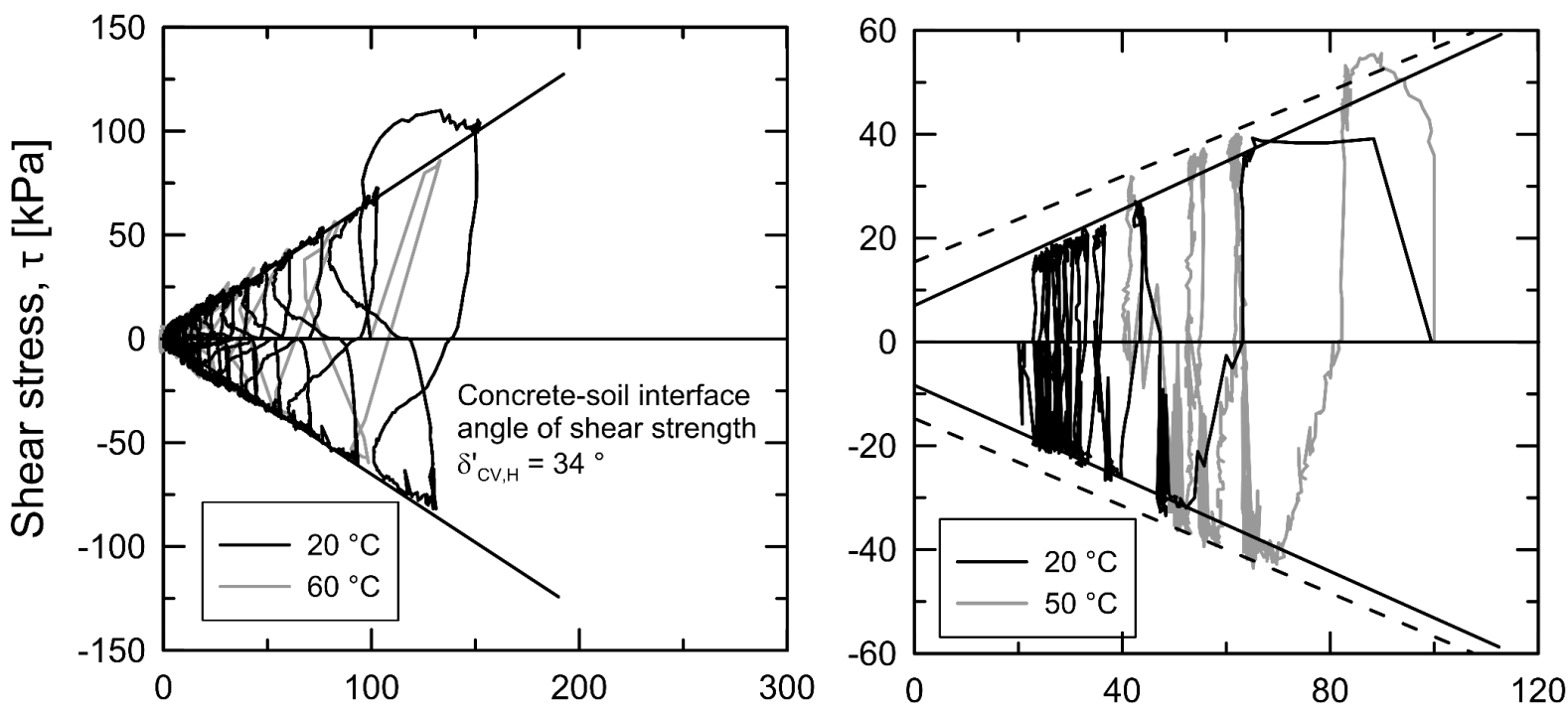

(a) Normal effective stress, $\sigma_{n}^{\prime}[\mathrm{kPa}]$ (b) Normal effective stress, $\sigma_{\mathrm{n}}^{\prime}[\mathrm{kPa}]$

Fig. 7: (a) Sand-concrete interface (high roughness): comparison between results at 20 and $60^{\circ} \mathrm{C}$. (b) Clay-concrete interface (medium roughness): comparison between results at 20 and $50{ }^{\circ} \mathrm{C}$ (redrawn after Di Donna et al. (2015)).

\section{PERFORMANCE-BASED DESIGN}

\section{Limit state design approach}


In a design based on the partial factor method, such as that foreseen by the so-called Eurocodes (EN 1990, 2002) in the European Union and by the ACI (ACI 318, 2008) and ANSI (AISC, 2010) codes in the United States of America, no limit state must be exceeded in all relevant design situations when design values for actions or effects of actions and resistances are introduced in the analysis models. According to Rotta Loria et al. (2018a) and considering the previous framework, thermal loads involve effects that can be neglected in the performance-based design of energy piles at ultimate limit states, provided that the design approach described in the following is employed. The unlikelihood of thermal loads exceeding geotechnical ultimate limit states can be highlighted, for example, by considering that in all situations and for any magnitude or type of thermal load applied to energy piles, the reactions provided by the soil below and above the null point of the shear stress compensate for each other, prevent the formation of a collapse mechanism and ensure equilibrium. The unlikelihood of thermal loads exceeding structural ultimate limit states can be highlighted, for example, by considering the capability of structural elements and structures characterized by sufficient ductility and rotation capacity to absorb the effects of imposed deformations, such as those caused by thermal loads (i.e., concept of auto-stress state).

Based on the previous considerations, the design and verification of energy piles at ultimate limit states can be considered as a conventional process against the action of mechanical loads only. In contrast, the design and verification of energy piles at serviceability limit states is a modified process that must account for the action of mechanical and thermal loads. The effects of thermal loads, in conjunction with those of mechanical loads, should be considered at serviceability limit states from the following aspects (Rotta Loria et al., 2018a): (i) single and group vertical displacement (e.g., differential and average) limitation, considering group effects; (ii) deflection and angular distortion control; (iii) compressive stress limitation; (iv) tensile stress limitation; and (v) crack control.

\section{Partial factors for thermal loads applied to energy piles}

Thermal loads involved with energy piles can be considered variable, indirect, free and static actions (Rotta Loria et al., 2018a), as can the thermal actions related to environmental loads be considered for buildings and bridges. The temperature changes applied to energy piles can be defined with reference to the heat inputs involved in the building energy design, the associated thermal powers for heating and cooling, the operation time and the thermal properties of the piles and ground. The resulting characteristic temperature changes are nominal values, $\Delta T_{k}$. In practice, characteristic temperature changes are likely to achieve (at maximum) $\Delta T_{k}=-15{ }^{\circ} \mathrm{C}$ when cooling thermal loads are applied to energy piles, whereas $\Delta T_{k}=+30{ }^{\circ} \mathrm{C}$ when heating thermal loads are applied to energy piles (Rotta Loria et al., 2018a).

To appropriately consider in the combinations of actions the influence of thermal loads, the following factors for the combination, frequent and quasi-permanent values of such variable actions are recommended, respectively (Rotta Loria et al., 2018a): $\psi_{0}=0.60, \psi_{1}=0.50$ and $\psi_{2}=0.50$. The proposed values of $\psi_{0}$ and $\psi_{1}$ coincide with those reported in the Eurocodes for buildings. They can be considered suitable for energy piles due to the similar probability of occurrence characterizing thermal actions applied to buildings and energy piles. The same values have been previously suggested by Burlon et al. (2013) and are recommended by the CFMS-SYNTEC-SOFFONS-FNTP (2017). The proposed value of $\psi_{2}$ differs from that reported in the Eurocodes for buildings (i.e., $\psi_{2}=0$ ) but coincides with that for bridges. This value has been defined considering that the average of variables can represent the accompanying values of variable actions, with reference to the data reported by Loveridge et al. (2016) that represent one of the few long-term monitoring examples currently available for energy piles. The proposed value of factor $\psi_{2}$ differs from the value of $\psi_{2}=0.20$ previously suggested by Burlon et al. (2013) and employed by the CFMS-SYNTEC-SOFFONS-FNTP (2017). 
When considering the combination of loads, the following must also be considered. (i) For heating thermal loads, it is not known a priori whether the involved effects make them the dominant load with respect to one or more compressive mechanical loads. Thus, different design combinations must be considered. One combination assumes that the effects of the thermal loads make them the dominant load ( $\Delta T_{k}=Q_{k, 1}$, where $Q_{k, 1}$ is the dominant variable load). The other combinations assume that the effects of the thermal loads do not make them the dominant load $\left(\Delta T_{k}=Q_{k, i}\right.$, where $Q_{k, i}$ is the $i$-th general variable load). (ii) For cooling thermal loads, a unique design combination must be considered, where $\Delta T_{k}=Q_{k, 1}$. In the aforementioned design combinations, the value of the characteristic temperature change $\Delta T_{k}$, instead of the value of the effect of this temperature change $Q_{k}\left(\Delta T_{k}\right)$, must be used. This approach is generally valid irrespective of whether analyses accounting for a reversible or irreversible mechanical behavior of the soil are performed. The reason for this is that no account for the hypothesis of superposition between the actions and their effects is made.

\section{Design approach}

The axial load capacity of piles is generally achieved for either the load for which a further increase in settlement does not induce an increase in load or for the load causing a settlement of $10 \%$ of the pile base diameter. When experimental evidence resorting to the results of full-scale in situ tests or laboratory tests may not be available, various theoretical formulations are available to estimate analytically the bearing capacity of energy piles (see, e.g., Poulos and Davis (1980) and Bowles (1988)). When entering in these formulations, the angles of shear strength of the soil and the pile-soil interface should be assumed to be under constant volume conditions. Such an approach yields suitable estimates of the bearing capacity (Powrie, 2013), especially in the absence of experimental data (Fleming et al., 2008).

Independent of the failure criterion employed to assess the geotechnical performance of energy piles, two aspects must be considered in any case to ensure adequate structural performance (Rotta Loria et al., 2018a):

- A design compressive strength of the reinforced concrete section (e.g., for no moments applied) at least equal to the design bearing capacity of the pile must be ensured. When this approach is not employed, design loads sustained from a geotechnical perspective may induce or exceed an ultimate limit state from a structural perspective. In contrast, the proposed approach is in favor of the development of ultimate limit states from a geotechnical perspective and guarantees a potential ductile collapse mechanism. Increasing the compressive strength of reinforced concrete sections can be achieved, e.g., through an increase of the concrete class or reinforcement. Higher concrete classes than needed are often applied for safety side considerations irrespective of the present prescription, such an evidence making this approach particularly compatible with the conventional practice. Attention must be given to the technical feasibility of using higher concrete classes with reference to the quality of the concrete, especially when dealing with bored piles.

- A minimum longitudinal reinforcement for the pile concrete cross-sectional area that can ensure ductility must be chosen. This minimum reinforcement ratio can be expressed as

$\rho_{r}=\rho_{r, \min } \geq \frac{f_{c t}}{f_{y}}$

where $f_{c t}$ and $f_{y}$ are appropriate values of the tensile strength of concrete and steel yield strength (a conservative value of $f_{c t}$ is the mean value of axial tensile strength of concrete, $\left.f_{c t m}\right)$. When this approach is employed, sufficient ductility capacity is ensured and structural ultimate limit states involving a collapse mechanism cannot occur. Concrete cracking should 
not be considered an issue but an ordinary property of concrete that needs to be controlled. Figure 8 provides evidence for this phenomenon by showing the actual relationship between the design traction axial load $N_{d}$ and the normalized axial displacement $\Delta w / L$ of a reinforced concrete member constituting an energy pile designed with reference to the proposed ductilityoriented approach. This relationship is compared with that of the same member characterized by the simultaneous occurrence of cracks (i.e., coinciding with the response of a single mean crosssection), as well as with the relationship of the reinforcement steel alone. Values of blocked normalized vertical displacement are plotted with reference to the worst-case scenario of fully restrained deformation conditions for the energy pile subjected to only the design cooling thermal loads considered thus far of $\Delta T_{d}=-7.5,-15$ and $-22.5^{\circ} \mathrm{C}$. The effective reinforcement ratio of $\rho_{r, \text { eff }}=0.72 \%$, the pile diameter of $D=1 \mathrm{~m}$, the concrete class $\mathrm{C} 30 / 37$ and the $\mathrm{B} 500 \mathrm{~B}$ reinforcement steel are considered.

Yet, when the action of thermal loads is considered throughout the geotechnical and structural design process of energy piles, two kinds of conditions should be considered for energy piles: (i) situations where the piles are free to move at their head and (ii) situations where the piles are restrained at their head because of the presence of a slab. Conditions (i) and (ii) conservatively analyze the pile vertical displacement and vertical stress, respectively. The slab stiffness $K_{h}=K_{\text {slab }}$ may be calculated according to Poulos and Davis (1974). In this context:

- The vertical stress variations caused by mechanical and thermal loads must be considered with respect to the entire length of energy piles, and the most stressed section must be verified (the effect of thermal loads varies along the pile length depending on the restraint conditions).

- The vertical displacement variations caused by mechanical and thermal loads must be considered with respect to the head of the energy piles (the effect of mechanical and thermal loads varies along the pile length but is only relevant at the pile head for the verifications).

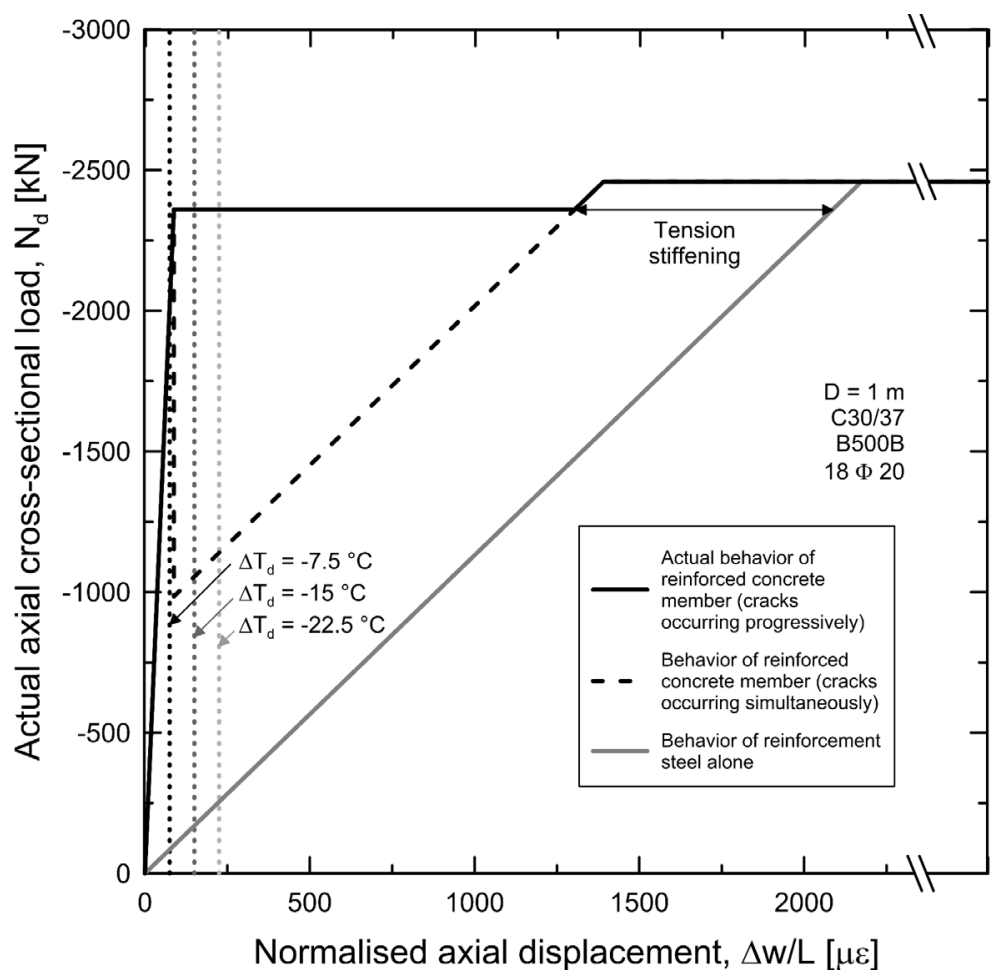

Fig. 8: Relationships between axial load and normalized axial displacement for energy piles made of reinforced concrete (modified after Rotta Loria et al. (2018a)). 


\section{CONCLUDING REMARKS}

This paper provides a framework about the thermo-mechanical behavior and the related geotechnical and structural performance of energy pile foundations, along with a novel performance-based design methodology for such geostructures subjected to mechanical and thermal loads. The following main conclusions can be drawn from this work:

- Thermal loads involve effects in energy piles that completely differ compared to those conventionally caused by mechanical loads applied to piles. The effects of thermal loads, applied alone or in conjunction with mechanical loads, must be considered in the analysis and design of energy piles.

- The effects of thermal loads can be neglected in the performance-based design of energy piles at ultimate limit states when the design approach discussed in this paper is employed. This consideration reduces the design and verification of energy piles at ultimate limit states as a conventional process against the action of mechanical loads only, while modifies the design and verification of energy piles at serviceability limit states as a process against the action of mechanical and thermal loads.

\section{ACKNOWLEDGMENTS}

I would like to gratefully acknowledge my mentor, Professor Lyesse Laloui, for the invaluable support, guidance and inspiration provided over several years of work at the Swiss Federal Institute of Technology in Lausanne (EPFL), which have contributed to the achievement of this work. The financial support of the Swiss National Science Foundation (project no. 160117, Division I-III) is highly appreciated.

\section{REFERENCES}

ACI 318 (2008): Building code requirements for structural concrete (ACI 318-08) and commentary, American Concrete Institute.

Adinolfi, M., Maiorano, R. M. S., Mauro, A., Massarotti, N. \& Aversa, S. (2018) On the influence of thermal cycles on the yearly performance of an energy pile. Geomechanics for Energy and the Environment: 10.1016/j.gete.2018.03.004.

Agar, J. G., Morgenstern, N. R. \& Scott, J. D. (1986) Thermal-expansion and pore pressure generation in oil sands. Canadian Geotechnical Journal 23(3):327-333.

Agar, J. G., Morgenstern, N. R. \& Scott, J. D. (1987) Shear strength and stress-strain behaviour of Athabasca oil sand at elevated temperatures and pressures. Canadian Geotechnical Journal 24(1):1-10.

AISC (2010)Specification for Structural Steel Buildings (ANSI/AISC 360-10). Chicago, Illinois, United States of America.

Akrouch, G. A., Sánchez, M. \& Briaud, J.-L. (2014) Thermo-mechanical behavior of energy piles in high plasticity clays. Acta Geotechnica 9(3):399-412.

Allani, M., Van Lysebetten, G. \& Huybrechts, N. (2017) Experimental and numerical study of the thermo-mechanical behaviour of energy piles for Belgian practice. In Advances in Laboratory Testing and Modelling of Soils and Shales. Springer, vol. 1, pp. 405-412.

Baldi, G., Hueckel, T. \& Pellegrini, R. (1988) Thermal volume changes of the mineral water-system in low-porosity clay soils. Canadian Geotechnical Journal 25(4):807-825.

Banerjee, A., Chakraborty, T. \& Matsagar, V. (2018) Evaluation of possibilities in geothermal energy extraction from oceanic crust using offshore wind turbine monopiles. Renewable and Sustainable Energy Reviews 92:685-700.

Batini, N., Rotta Loria, A. F., Conti, P., Testi, D., Grassi, W. \& Laloui, L. (2015) Energy and geotechnical behaviour of energy piles for different design solutions. Applied Thermal Engineering 
86(1):199-213.

Bourne-Webb, P., Bodas Freitas, T. \& Freitas Assunção, R. (2016) Soil-pile thermal interactions in energy foundations. Geotechnique 66(2):167-171.

Bourne-Webb, P. J., Amatya, B. \& Soga, K. (2011) A framework for understanding energy pile behaviour. Proceedings of the ICE-Geotechnical Engineering 166(2):170-177.

Bourne-Webb, P. J., Amatya, B. L., Soga, K., Amis, T., Davidson, C. \& Payne, P. (2009) Energy pile test at Lambeth College, London: geotechnical and thermodynamic aspects of pile response to heat cycles. Geotechnique 59(3):237-248.

Bowles, J. E. (1988) Foundation analysis and design. Singapore, McGraw-Hill.

Burghignoli, A., Desideri, A. \& Miliziano, S. (2000) A laboratory study on the thermomechanical behaviour of clayey soils. Canadian Geotechnical Journal 37(4):764-780.

Burlon, S., Habert, J., Szymkievicz, F., Suryatriyastuti, M. \& Mroueh, H. (2013) Towards a design approach of bearing capacity of thermo-active piles. In European Geothermal Congress. pp. 1-6

Campanella, R. G. \& Mitchell, J. K. (1968) Influence of the temperature variations on soil behaviour. Journal of the Soil Mechanics and Foundation Engineering Division ASCE 94(SM3):709-734.

Cekerevac, C. \& Laloui, L. (2004) Experimental study of thermal effects on the mechanical behaviour of a clay. International journal for numerical and analytical methods in geomechanics 28(3):209-228.

CFMS-SYNTEC-SOFFONS-FNTP (2017) Recommandations pour la conception, le dimensionnement et la mise en cuvre des géostructures thermiques. pp. 120.

Chen, Y., Xu, J., Li, H., Chen, L., Ng, C. W. \& Liu, H. (2017) Performance of a prestressed concrete pipe energy pile during heating and cooling. Journal of Performance of Constructed Facilities 31(3):06017001.

Demars, K. R. \& Charles, R. D. (1981) Soil volume changes induced by temperature cycling. Canadian Geotechnical Journal 19(2):188-194.

Di Donna, A., Ferrari, A. \& Laloui, L. (2015) Experimental investigations of the soil-concrete interface: physical mechanisms, cyclic mobilisation and behaviour at different temperatures. Canadian Geotechnical Journal 53(4):659-672.

Di Donna, A. \& Laloui, L. (2014) Numerical analysis of the geotechnical behaviour of energy piles. International journal for numerical and analytical methods in geomechanics 39(8):861-888.

Di Donna, A. \& Laloui, L. (2015) Response of soil subjected to thermal cyclic loading: experimental and constitutive study. Engineering Geology 190(1):65-76.

Di Donna, A., Rotta Loria, A. F. \& Laloui, L. (2016) Numerical study on the response of a group of energy piles under different combinations of thermo-mechanical loads. Computers and Geotechnics 72(1):126-142.

EN 1990 (2002) Eurocode: Basis of structural design. London, United Kingdom, pp. 90.

EN 1992 (2004) Design of concrete structures - Part 1-1: General rules and rules for buildings. London, United Kingdom, pp. 225.

Eslami, H., Rosin-Paumier, S., Abdallah, A. \& Masrouri, F. (2017) Pressuremeter test parameters of a compacted illitic soil under thermal cycling. Acta Geotechnica:1-14.

Fleming, K., Weltman, A., Randolph, M. \& Elson, K. (2008) Piling engineering. CRC press.

Gawecka, K. A., Taborda, D. M., Potts, D. M., Cui, W., Zdravković, L. \& Haji Kasri, M. S. (2016) Numerical modelling of thermo-active piles in London Clay. Proceedings of the Institution of Civil Engineers-Geotechnical Engineering:1-19.

Goode, J., III \& McCartney, J. S. (2015) Centrifuge modeling of boundary restraint effects in energy foundations. Journal of geotechnical and geoenvironmental engineering 141(8):04015034.

Ground Source Heat Pump Association, N. E. C. (2012) Thermal pile design, installation \& materials standards. Davy Avenue, Knowlhill, Milton Keyenes, pp. 86.

Hueckel, T. \& Baldi, G. (1990) Thermoplasticity of saturated clays - experimental constitutive study. Journal of geotechnical engineering 116(12):1778-1796.

Jeong, S., Min, H. \& Lee, J. K. (2014) Thermally induced mechanical response of energy piles in axially loaded pile groups. Applied Thermal Engineering 71(1):608-615. 
Jelušič P, Žlender B. Determining optimal designs for conventional and geothermal energy piles. Renewable Energy. 2018: 10.1016/j.renene.2018.08.016

Kalantidou, A., Tang, A. M., Pereira, J. \& Hassen, G. (2012) Preliminary study on the mechanical behaviour of heat exchanger pile in physical model. Geotechnique 62(11):1047-1051.

Knellwolf, C., Peron, H. \& Laloui, L. (2011) Geotechnical analysis of heat exchanger piles. Journal of geotechnical and geoenvironmental engineering 137(10):890-902.

Kramer, C. A. \& Basu, P. (2014) Performance of a model geothermal pile in sand In Proceedings of 8th International Conference on Physical Modelling in Geotechnics (Balkema (ed)). CRC Press, pp. 771-777. Laloui, L., Moreni, M. \& Vulliet, L. (2003) Comportement d'un pieu bi-fonction, fondation et échangeur de chaleur. Canadian Geotechnical Journal 40(2):388-402.

Laloui, L., Nuth, M. \& Vulliet, L. (2006) Experimental and numerical investigations of the behaviour of a heat exchanger pile. International journal for numerical and analytical methods in geomechanics 30(8):763-781.

Liu, H.-1., Wang, C.-1., Kong, G.-q. \& Bouazza, A. (2018) Ultimate bearing capacity of energy piles in dry and saturated sand. Acta Geotechnica: 10.1007/s11440-018-0661-6.

Loveridge, F., Powrie, W., Amis, T., Wischy, M. \& Kiauk, J. (2016) Long term monitoring of CFA energy pile schemes in the UK. In Energy Geotechnics. CRC Press, pp. 585-592

Luo, J., Zhao, H., Gui, S., Xiang, W. \& Rohn, J. (2017) Study of thermal migration and induced mechanical effects in double U-tube energy piles. Computers and Geotechnics 91:1-11.

Marto, A., Amaludin, A. \& Hatta Bin Satar, M. (2015) Experiments on shallow geothermal energy model piles embedded in soft soil. Electronic Journal of Geotechnical Engineering 20:12687-12698.

McCartney, J. S. \& Murphy, K. D. (2012) Strain distributions in full-scale energy foundations. DFI Journal 6(2):26-38.

McCartney, J. S. \& Murphy, K. D. (2017) Investigation of potential dragdown/uplift effects on energy piles. Geomechanics for Energy and the Environment 10:21-28.

McCartney, J. S., Xiao, Y., Liu, H. \& Liu, H. (2018) Influence of temperature on the volume change behavior of saturated sand. Geotechnical Testing Journal 41(4).

Mimouni, T. \& Laloui, L. (2014) Towards a secure basis for the design of geothermal piles. Acta Geotechnica 9(3):355-366.

Mimouni, T. \& Laloui, L. (2015) Behaviour of a group of energy piles. Canadian Geotechnical Journal 52(12):1913-1929.

Murphy, K. \& McCartney, J. S. (2015) Seasonal response of energy foundations during building operation. Geotechnical and Geological Engineering 33(2):343-356.

Murphy, K. D., McCartney, J. S. \& Henry, K. S. (2015) Evaluation of thermo-mechanical and thermal behavior of full-scale energy foundations. Acta Geotechnica 10(2):1-17.

Ng, C. W. W., Gunawan, A., Shi, C., Ma, Q. \& Liu, H. (2016a) Centrifuge modelling of displacement and replacement energy piles constructed in saturated sand: a comparative study. Géotechnique Letters 6(1):34-38.

Ng, C. W. W., Ma, Q. J. \& Gunawan, A. (2016b) Horizontal stress change of energy piles subjected to thermal cycles in sand. Computers and Geotechnics 78:54-61.

Ng, C. W. W., Shi, C., Gunawan, A. \& Laloui, L. (2014) Centrifuge modelling of energy piles subjected to heating and cooling cycles in clay. Géotechnique Letters 4(October-December):310-316.

Ng, C. W. W., Shi, C., Gunawan, A., Laloui, L. \& Liu, H. L. (2015) Centrifuge modelling of heating effects on energy pile performance in saturated sand. Canadian Geotechnical Journal 52(8): 1045-1057.

Ng, C. W. W. \& Zhou, C. (2017) Plastic deformations of unsaturated fine-grained soils under cyclic thermo-mechanical loads. In Advances in Laboratory Testing and Modelling of Soils and Shales.) Springer, pp. 14-28.

Nguyen, V. T., Tang, A. M. \& Pereira, J.-M. (2017) Long-term thermo-mechanical behavior of energy pile in dry sand. Acta Geotechnica:1-9.

Olgun, C. G., Ozudogru, T. Y. \& Arson, C. (2014) Thermo-mechanical radial expansion of heat exchanger piles and possible effects on contact pressures at pile-soil interface. Géotechnique Letters 
4(July-September):170-178.

Pasten, C. \& Santamarina, J. C. (2014) Thermally induced long-term displacement of thermoactive piles. Journal of geotechnical and geoenvironmental engineering 140(5):06014003.

Plum, R. L. \& Esrig, M. I. (1969) Some temperature effects on soil compressibility and pore water pressure. In Highway Research Board Special Report, vol. 103.

Poulos, H. G. \& Davis, E. H. (1974) Elastic solutions for soil and rock mechanics. Wiley.

Poulos, H. G. \& Davis, E. H. (1980) Pile foundation analysis and design. New York, Wiley.

Powrie, W. (2013) Soil mechanics: concepts and applications. CRC Press.

Rammal, D., Mroueh, H. \& Burlon, S. (2018) Impact of thermal solicitations on the design of energy piles. Renewable and Sustainable Energy Reviews 92:111-120.

Rotta Loria, A. F., Bocco, M., Garbellini, C., Muttoni, A. \& Laloui, L. (2018a) The role of thermal loads in the performance-based design of energy piles. Under review.

Rotta Loria, A. F., Gunawan, A., Shi, C., Laloui, L. \& Ng, C. W. (2015) Numerical modelling of energy piles in saturated sand subjected to thermo-mechanical loads. Geomechanics for Energy and the Environment 1(1):1-15.

Rotta Loria, A. F. \& Laloui, L. (2016) The interaction factor method for energy pile groups. Computers and Geotechnics 80:121-137.

Rotta Loria, A. F. \& Laloui, L. (2017a) Displacement interaction among energy piles bearing on stiff soil strata. Computers and Geotechnics 90:144-154.

Rotta Loria, A. F. \& Laloui, L. (2017b) The equivalent pier method for energy pile groups. Geotechnique 67(8):691-702.

Rotta Loria, A. F. \& Laloui, L. (2018c) Group action effects caused by various operating energy piles. Geotechnique 68(9):834-841.

Rotta Loria, A. F. \& Laloui, L. (2017c) Thermally induced group effects among energy piles. Geotechnique 67(5):374-393.

Rotta Loria, A. F. \& Laloui, L. (2019) Thermo-mechanical schemes for energy piles. International Symposyum on Energy Geotechnics - SEG2018:218-225, 10.1007/978-3-319-99670-7_28.

Rotta Loria, A. F., Vadrot, A. \& Laloui, L. (2017) Effect of non-linear soil deformation on the interaction among energy piles. Computers and Geotechnics 86:9-20.

Rotta Loria, A. F., Vadrot, A. \& Laloui, L. (2018b) Analysis of the vertical displacement of energy pile groups. Geomechanics for Energy and the Environment 16:1-14.

Rui, Y. \& Soga, K. (2018) Thermo-hydro-mechanical coupling analysis of a thermal pile. Proceedings of the Institution of Civil Engineers-Geotechnical Engineering:1-65.

Saggu, R. \& Chakraborty, T. (2015) Cyclic thermo-mechanical analysis of energy piles in sand. Geotechnical and Geological Engineering 33(1):1-22.

Saggu, R. \& Chakraborty, T. (2016) Thermomechanical response of geothermal energy pile groups in sand. International Journal of Geomechanics 16(4):04015100.

Salciarini, D., Ronchi, F., Cattoni, E. \& Tamagnini, C. (2015) Thermomechanical effects induced by energy piles operation in a small piled raft. International Journal of Geomechanics 15(2):04014042.

Salciarini, D., Ronchi, F. \& Tamagnini, C. (2017) Thermo-hydro-mechanical response of a large piled raft equipped with energy piles: a parametric study. Acta Geotechnica: 10.1007/s1144.

SIA-D0190 (2005) Utilisation de la Chaleur du Sol par des Ouvrages de Fondation et de Soutènement en Béton. Guide pour la Conception, la Realisation et la Maintenance. Zurich, Switzerland.

Stewart, M. A. \& McCartney, J. S. (2014) Centrifuge modeling of soil-structure interaction in energy foundations. Journal of geotechnical and geoenvironmental engineering 140(4):04013044.

Suryatriyastuti, M., Burlon, S. \& Mroueh, H. (2015) On the understanding of cyclic interaction mechanisms in an energy pile group. International journal for numerical and analytical methods in geomechanics:10.1002/nag.2382.

Suryatriyastuti, M., Mroueh, H. \& Burlon, S. (2012) Understanding the temperature-induced mechanical behaviour of energy pile foundations. Renewable and Sustainable Energy Reviews 16(5):3344-3354.

Suryatriyastuti, M., Mroueh, H. \& Burlon, S. (2014) A load transfer approach for studying the cyclic 
behavior of thermo-active piles. Computers and Geotechnics 55(1):378-391.

Sutman, M., Olgun, C. \& Brettmann, T. (2015) Full-scale field testing of energy piles In Proceedings of IFCEE 2015. ASCE vol. 1, pp. 1638-1647.

Sutman, M., Olgun, G., Laloui, L. \& Brettmann, T. (2017) Effect of end-restraint conditions on energy pile behavior. In Geotechnical Frontiers 2017, pp. 165-174.

Vega, A. \& McCartney, J. S. (2014) Cyclic heating effects on thermal volume change of silt. Environmental Geotechnics 2(5):257-268.

Wang, B., Bouazza, A., Singh, R. M., Haberfield, C., Barry-Macaulay, D. \& Baycan, S. (2014) Posttemperature effects on shaft capacity of a full-scale geothermal energy pile. Journal of geotechnical and geoenvironmental engineering 141(4):04014125.

Xiao, J., Luo, Z., Martin, J. R., Gong, W. \& Wang, L. (2016) Probabilistic geotechnical analysis of energy piles in granular soils. Engineering Geology 209:119-127

Yavari, N., Tang, A. M., Pereira, J.-M. \& Hassen, G. (2014) Experimental study on the mechanical behaviour of a heat exchanger pile using physical modelling. Acta Geotechnica 9(3):385-398.

Yavari, N., Tang, A. M., Pereira, J.-M. \& Hassen, G. (2016a) Effect of temperature on the shear strength of soils and the soil-structure interface. Canadian Geotechnical Journal 53(999):1-9.

Yavari, N., Tang, A. M., Pereira, J.-M. \& Hassen, G. (2016b) Mechanical behaviour of a small-scale energy pile in saturated clay. Geotechnique 66(11):878-887.

You, S., Cheng, X., Guo, H. \& Yao, Z. (2016) Experimental study on structural response of CFG energy piles. Applied Thermal Engineering 96(1):640-651.

Zhou, C., Ng, C. W. W. \& Wang, S. (2017) Modelling volume changes of sand under thermal loads: a preliminary attempt. Géotechnique Letters 7(1):68-72. 